\title{
Study Material
}

National Cancer Institute

\section{Source}

National Cancer Institute. Study Material. NCI Thesaurus. Code C93406.

Physical supplies provided by an individual company, institution, or organization for the conduct of research. 